Article

\title{
Quartz Microcrystal-Hybridized Organosilicone Encapsulant with Enhanced Optical and Thermal Performances
}

\author{
Xin Chen ${ }^{1,2,+}$, Yancong Feng ${ }^{1,2,+}$, Xiao Wang ${ }^{1,2}$, En Li ${ }^{1,2}$, Yao Wang ${ }^{1,2}$, Lingling Shui ${ }^{1,2}$, \\ Hao Li ${ }^{1,2, *}$, Nan $\mathrm{Li}^{3,4}$ and Guofu Zhou ${ }^{1,2,3,4, *}$ \\ 1 Guangdong Provincial Key Laboratory of Optical Information Materials and Technology \& Institute of \\ Electronic Paper Displays, South China Academy of Advanced Optoelectronics, \\ South China Normal University, Guangzhou 510006, China; chenxinchauncey@163.com (X.C.); \\ fengyancong@m.scnu.edu.cn (Y.F.); wang2009xiao@163.com (X.W.); lien1016@163.com (E.L.); \\ wangyao@m.scnu.edu.cn (Y.W.); shuill@m.scnu.edu.cn (L.S.) \\ 2 National Center for International Research on Green Optoelectronics, South China Normal University, \\ Guangzhou 510006, China \\ 3 Shenzhen Guohua Optoelectronics Tech. Co. Ltd., Shenzhen 518110, China; nan.li@guohua-oet.com \\ 4 Academy of Shenzhen Guohua Optoelectronics, Shenzhen 518110, China \\ * $\quad$ Correspondence: haoli@scnu.edu.cn (H.L.); guofu.zhou@m.scnu.edu.cn (G.Z.); Tel.: +86-20-3931-4813 (H.L.) \\ $\dagger$ These authors contributed equally to this work.
}

Received: 30 November 2017; Accepted: 13 January 2018; Published: 16 January 2018

\begin{abstract}
Encapsulant is one determining factor underpinning the device lifetimes of organic optoelectronics. However, encapsulant seriously needs improvement in optical, thermal, and mechanical properties, especially to develop organic light emitting diodes. In this study, we prepared an in situ crosslinked organosilane composite containing benzyloxy and glycidyl-modified quartz microcrystal (mQMC) as high performance encapsulant. In the present work, methylphenylsilanediol (MPSD) was introduced as a novel crosslinker to impart appropriate structural strength. Along with increasing mQMC fillers, this organosilane system shows improved properties, such as refractive index, thermal stability, and storage modulus. Specifically, these hybridized mQMCs in the organosilane framework may facilitate an approximate two-fold increase $(0.238 \mathrm{~W} /(\mathrm{m} \cdot \mathrm{K}))$ in overall thermal conductivity at the determined concentration.
\end{abstract}

Keywords: organosilane; quartz microcrystal; encapsulant; refractive index; thermal conductivity

\section{Introduction}

In recent years, organic electronics have attracted more and more interest in a range of fields, e.g., display, sensor array, lighting panel, photovoltaic module and so on. As the first commercial application, organic light emitting diodes (OLEDs) reduce energy consumption and decrease device complexity compared to conventional liquid crystal displays [1]. However, their extremely sensitive components remarkably weaken device reliability. Naturally, encapsulant becomes one determining factor to provide hermetic protection for OLEDs. In this process, optical, thermal, mechanical, water, and oxygen barriers are involved in the specific demands of encapsulant performance [2].

As a frame material, epoxy is widely used as encapsulant due to its good adhesion, strong mechanical strength and rapid curing processing, but is still limited by poor moisture resistance, weak thermal stability, and a low refractive index [3-7]. On the contrary, organosilicone resin possesses a relatively high refractive index, strong moisture resistance, and good thermal stability, as well as good compatibility with glass substrate [8-12]. Therefore, organosilicone has gradually become a more suitable encapsulant candidate with high performance. 
However, the modification or formula regulation of frame material falls short of the demands for an excellent OLED encapsulant. Typically, the introduction of high polarization groups or atoms to the matrix [13-16]— such as phenyl group [8,17-22], sulfur [15], fluorine [12,17], phosphor [18], and nitrogen [18] — can effectively heighten the refractive index. On the other hand, some nanoparticles—e.g., $\mathrm{TiO}_{2}[19,23]$ and $\mathrm{ZrO}_{2}$ [3]—can be also introduced to achieve a desirable refractive index of encapsulant by hybridization. At the same time, the addition of similar nanoparticles-such as boron nitride nanosheets [7,24,25], graphene nanosheets [9,10], black phosphorus [26], ZnO [27], silicon carbide [28], core-shell $\mathrm{Ag} @ \mathrm{SiO}_{2}$ [29], and carbon nanotube [30]—will contribute significantly to the thermal conductivity of encapsulant materials.

In this work, we chose cheap and compatible quartz microcrystal (QMC) as filler and crosslinkers, and chose novel methylphenylsilanediol (MPSD) as molecular crosslinker, to construct a highly in situ crosslinked organosilicone network. Hereinto, surface modification of QMC will not only bring abundant phenyl groups to this organosilicone system for high refractive index, but also increase crosslinking density for good mechanical strength and thermal stability. Especially, high thermal conductivity of QMC $[8 \mathrm{~W} /(\mathrm{m} \cdot \mathrm{K})]$ also facilitates overall thermal diffusion in the system. Moreover, MPSD will favor appropriate structural rigidity of organosilicone encapsulant.

\section{Materials and Methods}

\subsection{Materials}

Dichloromethylphenylsilane (98\%), 3-glycidyloxypropyl trimethoxysilane (97\%, GMS), vinyltrimethoxysilane ( $>98 \%$, VTMS), and methyldiethoxysilane ( $>98 \%$, MDES) were all provided by J\&K Chemical Technology (Beijing, China). Barium hydroxide monohydrate $\left(97 \%, \mathrm{Ba}(\mathrm{OH})_{2} \cdot \mathrm{H}_{2} \mathrm{O}\right)$ was purchased from HWRK Chemical (Beijing, China). Quartz microcrystal (mean size: $\sim 5 \mu \mathrm{m}$ ) was bought from Lianyungang Donghai Silica Powder Co., Ltd. (Jiangsu, China). Both Pt Karstedt's catalyst (Platinum(0)-1,3-divinyl-1,1,3,3-tetramethyldisiloxane complex solution in $p$-xylene $(\sim 2 \% \mathrm{Pt})$, Sigma-Aldrich, St. Louis, MO, USA) and Amberlite IRC76 (Alfa Aesar, Haverhill, MA, USA) were directly used. All other reagents and organic solvents are of analytic reagent (AR) without further treatment prior to use.

\subsection{Synthesis of MPSD}

MPSD was obtained by hydrolysis reaction (see Figure 1A) [31]. Typically, dichloromethylphenylsilane was dropwise added to the mixture of triethylamine, acetone, ultrapure water, and ether for $1 \mathrm{~h}$ while stirring at $0{ }^{\circ} \mathrm{C}$. Then, the redundant triethylamine hydrochloride was removed by vacuum filtration. Subsequently, the resulting filtrate was concentrated to one-tenth of the initial volume and then precipitated in excess cold $n$-hexane. After freezing for $24 \mathrm{~h}$, the final MPSD was separated out and collected by vacuum filtration.

\subsection{Modification of Quartz Microcrystal}

Both a determined amount of QMC and excess benzyl alcohol were added into a stainless vessel and then heated up to $240{ }^{\circ} \mathrm{C}$ for $96 \mathrm{~h}$. Afterwards, benzyloxy-modified QMCs were obtained by high speed centrifugation for $10 \mathrm{~min}$. Next, these QMCs were mixed fully with GMS in tetrahydrofuran under sonication for $2 \mathrm{~h}$. Finally, all the products, benzyloxy, and glycidyl-modified QMC (mQMC) were concentrated to $5 \mathrm{~mL}$ in dry argon flow (see Figure 1B) [3].

\subsection{Synthesis of Vinylmethylphenylsiloxane Resin (VMPS)}

VMPS was obtained by sol-gel condensation of VTMS and MPSD (molar ratio: 1:1) in $p$-xylene (10 wt. \%) at $80{ }^{\circ} \mathrm{C}$ while stirring for $4 \mathrm{~h}$, using $\mathrm{Ba}(\mathrm{OH})_{2} \cdot \mathrm{H}_{2} \mathrm{O}(0.1 \mathrm{~mol} \%)$ as catalyst (see Figure $\left.1 \mathrm{C}\right)$ [32]. After the reaction proceeded for $2 \mathrm{~h}$, the catalyst was filtered out with a $10 \mu \mathrm{m}$ syringe filter. 
The dropwise addition of mQMC into the reacting mixture followed immediately. Finally, all the volatile components were removed in vacuum.

\subsection{Synthesis of Methylphenylsiloxane Resin (MPS)}

Similarly, MPS was synthesized by sol-gel condensation of MDES and MPSD (molar ratio: 1:1.5) at $100{ }^{\circ} \mathrm{C}$ while stirring for $12 \mathrm{~h}$, using Amberlite IRC76 (0.1 mol \%) as acidic catalyst (see Figure 1C) [32]. Once the reaction proceeded for $2 \mathrm{~h}$, the catalyst was filtered out with a $10 \mu \mathrm{m}$ syringe filter. Then the dropwise addition of $\mathrm{mQMC}$ into the reacting mixture followed immediately. Finally, all the volatile components were removed in vacuum.

\subsection{Fabrication of Quartz-Organosilicone Composite}

The quartz-organosilicone composite was synthesized by hydrosilylation of VMPS and MPS using Pt Karstedt's catalyst while stirring for $2 \mathrm{~h}$ (see Figure 1D) [32]. Afterwards, the mixture was homogenized by sonication for $1 \mathrm{~h}$ and then cast into a customized stainless steel mold. Finally, the sample was cured at $90^{\circ} \mathrm{C}$ for $1 \mathrm{~h}$, followed by heating at $150{ }^{\circ} \mathrm{C}$ for $2 \mathrm{~h}$ in air.

\subsection{Chemical Characterizations}

The chemical structure of MPSD was tested by electron ionization mass spectrometer (EI-MS) using a NexION 300 supplied by PerkinElmer (Waltham, MA, USA). The surface modification of QMC was identified by Fourier transform infrared spectrometer (FTIR) using a Vertex 70 supplied by Bruker (Karlsruhe, Germany) in a spectral range of $4000-400 \mathrm{~cm}^{-1}$ with the resolution of $2 \mathrm{~cm}^{-1}$. Samples were prepared using $\mathrm{KBr}$ plate method.

\subsection{Optical Measurements}

The transmittances of the final quartz-organosilicone composite films were measured by ultraviolet-visible-near infrared spectrophotometer (UV-vis-NIR) using a LAMBDA 950 supplied by PerkinElmer in the wavelength range of $400-700 \mathrm{~nm}$. All the thicknesses of the samples were $1 \mathrm{~mm}$. The measurements of refractive index were performed by refractometer using a DR-2 supplied by ATAGO (Tokyo, Japan) at $589 \mathrm{~nm}$ and $25^{\circ} \mathrm{C}$.

\subsection{Thermal Analysis}

The thermal stability of the samples was examined by thermal gravimetric analysis (TGA) using a TGA 2 supplied by METTLER TOLEDO (Greifensee, Switzerland) in the temperature range from $25^{\circ} \mathrm{C}$ to $1000^{\circ} \mathrm{C}$ with a heating rate of $10^{\circ} \mathrm{C} / \mathrm{min}$ in nitrogen atmosphere (flow rate: $50 \mathrm{~mL} / \mathrm{min}$ ).

The thermal conductivity was determined by laser thermal conductivity analysis using a LFA447 supplied by NETZSCH (Selb, Germany) at $25^{\circ} \mathrm{C}$. All the sizes of samples were $10 \times 10 \mathrm{~mm}^{2}$ with the thickness of $1 \mathrm{~mm}$.

\subsection{Mechanical Test}

The mechanical performance was tested by dynamic mechanical thermal analysis (DMA) using a DMA 1 supplied by METTLER TOLEDO (Greifensee, Switzerland) in a temperature range from $50{ }^{\circ} \mathrm{C}$ to $260{ }^{\circ} \mathrm{C}$ with a heating rate of $5^{\circ} \mathrm{C} / \mathrm{min}$ at $1 \mathrm{~Hz}$ in the shear mode.

\section{Results and Discussion}

As the best candidate for encapsulant, organosilicone still needs to be improved in optical and thermal performances. In the present work, both MPSD crosslinker and QMC additive were introduced into the siloxane matrix by four-step fabrication (see Figure 1). The related descriptions of fabrication are presented in the Materials and Methods section and Supporting Information in detail. MPSD was obtained by hydrolysis reaction as shown in Figure 1A. Hereinto MPSD is so active that reacts to form 
a series of different oligomers. As shown in Figure 2, there are a dimer peak at $288 \mathrm{~m} / \mathrm{z}$, and a trimer peak at $424 \mathrm{~m} / z$, much stronger than the monomer peak at $154 \mathrm{~m} / \mathrm{z}$. Although the obtained product is a mixture of MPSD and its oligomers, their good solubility in two silane monomers-VTMS and MDES—contribute greatly to the following coupling reactions.

A<smiles>C[Si](Cl)(Cl)c1ccccc1</smiles>

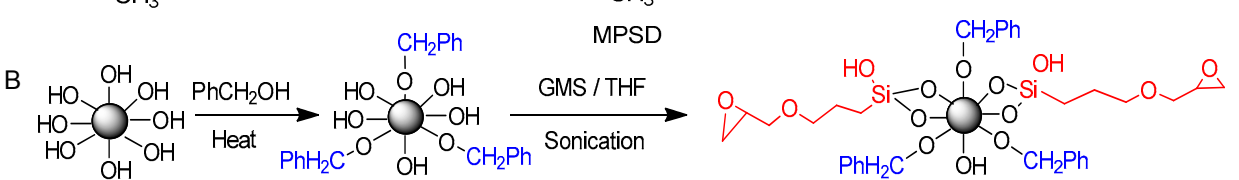

C
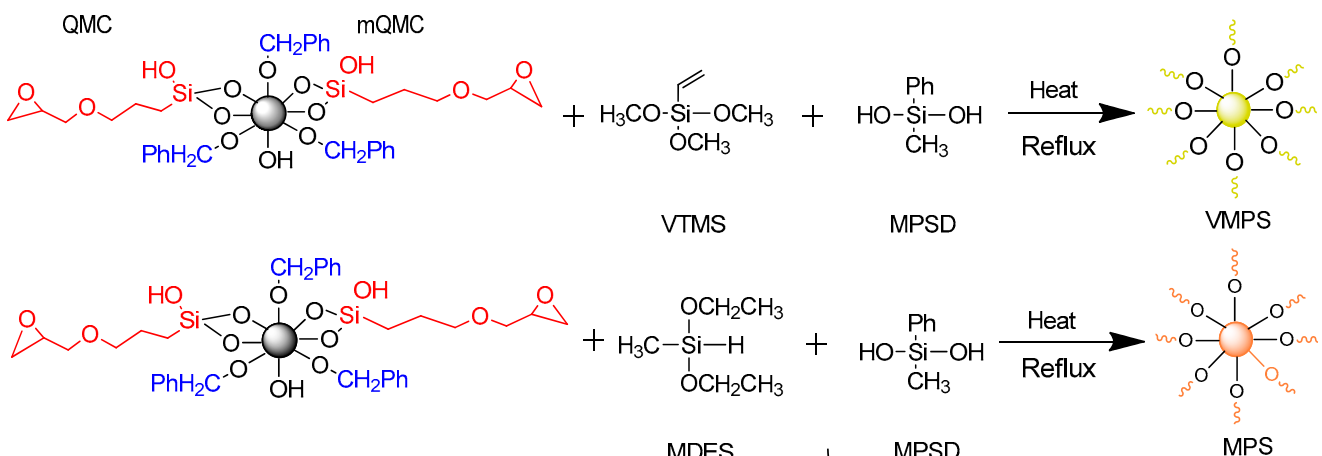

D
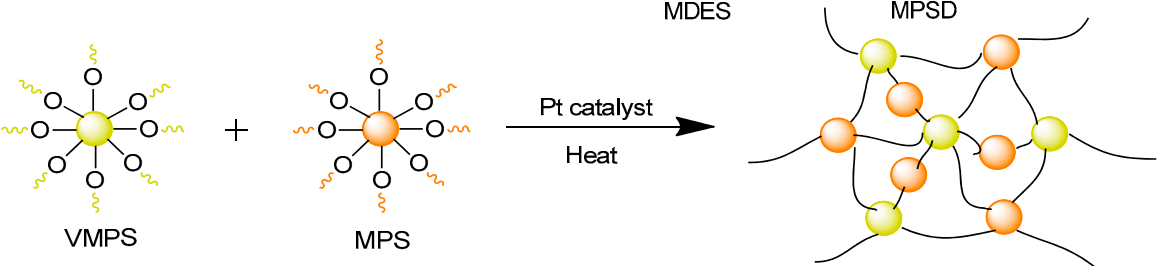

Figure 1. Synthesis routes of (A) MPSD; (B) surface-modified QMC; (C) two intermediate resins_VMPS and MPS; and (D) final quartz-organosilane composite.

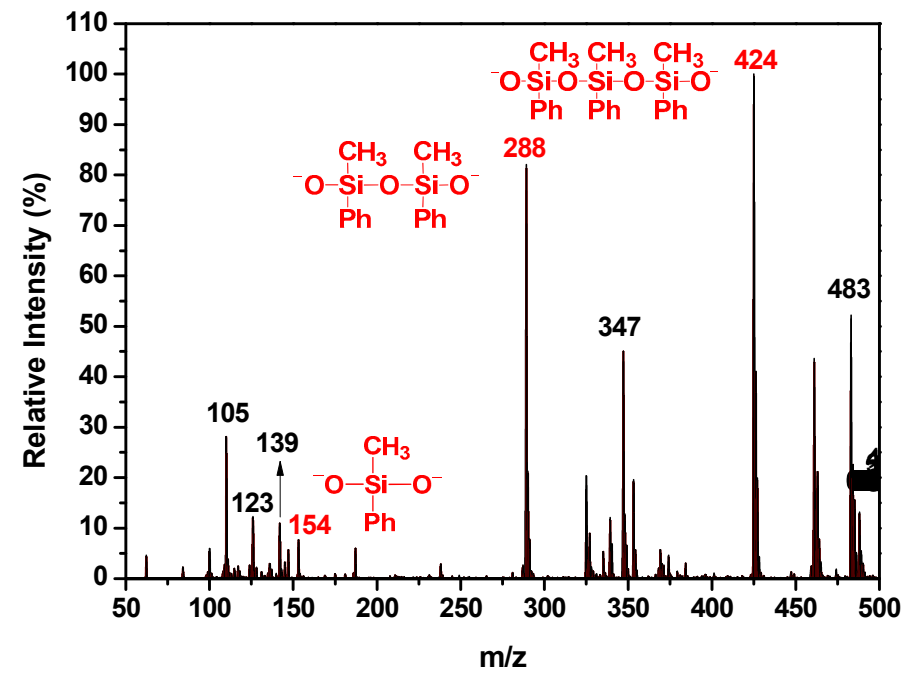

Figure 2. Mass spectrum of MPSD. The related peaks list below: $105(m / z, \mathrm{SiPh}), 123(\mathrm{~m} / z, \mathrm{SiOPh})$, $139\left(m / z, \mathrm{Si}(\mathrm{OH})_{2} \mathrm{Ph}\right), 154\left(m / z, \mathrm{SiO}_{2} \mathrm{PhCH}_{3}\right), 288\left(m / z, \mathrm{Si}_{2} \mathrm{O}_{3} \mathrm{Ph}_{2} \mathrm{C}_{2} \mathrm{H}_{6}\right), 347\left(m / z, \mathrm{Si}_{3} \mathrm{O}_{4} \mathrm{Ph}_{2} \mathrm{C}_{3} \mathrm{H}_{9}\right)$, $424\left(m / z, \mathrm{Si}_{3} \mathrm{O}_{4} \mathrm{Ph}_{3} \mathrm{C}_{3} \mathrm{H}_{9}\right), 483\left(m / z, \mathrm{Si}_{4} \mathrm{O}_{5} \mathrm{Ph}_{3} \mathrm{C}_{4} \mathrm{H}_{12}\right)$. 
In fact, benzyloxy- and glycidyl-modified QMC (mQMC) (see Figure 1B) also act as another kind of crosslinker with extremely high crosslinking intensity. Figure 3 obviously displays the absorption bands of benzyl groups at $1400-1600 \mathrm{~cm}^{-1}$ [3]. This proves that the benzyl group is successfully grafted to the surface of QMC. It may effectively enhance the compatibility of QMC with the organosilicone frameworks, owing to similar chemical groups.

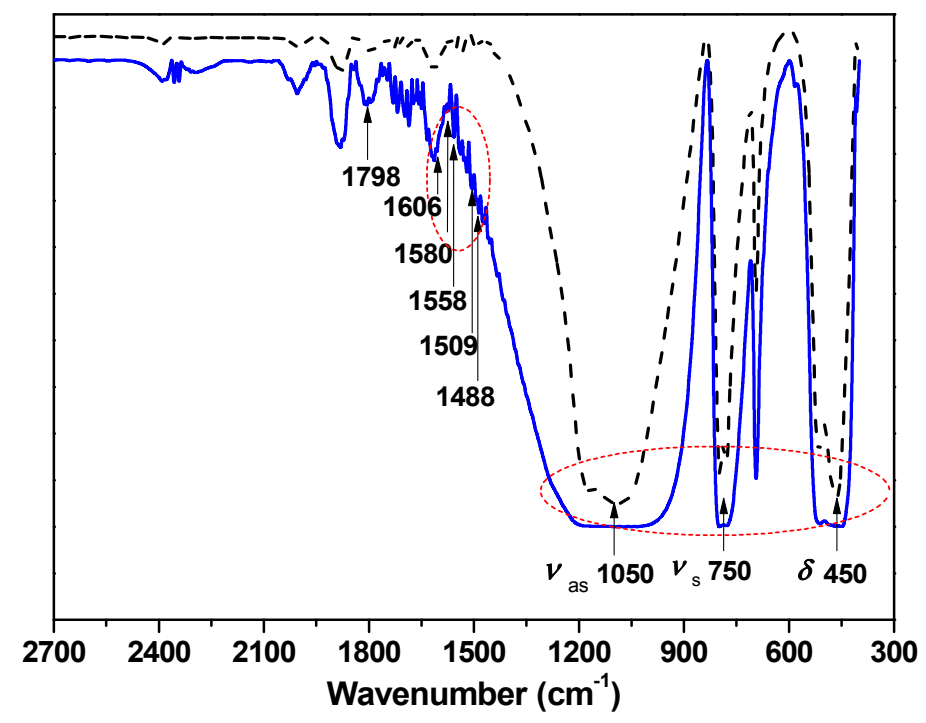

Figure 3. FTIR spectra of quartzes before and after surface modification with benzyl alcohol. The dash black line is quartz without modification and the solid blue line is the modified quartz. The related peaks list below: $450 \mathrm{~cm}^{-1}\left(\delta,-\mathrm{Si}-\mathrm{O}\right.$ linked with quartz microcrystal), $750 \mathrm{~cm}^{-1}\left(v_{\mathrm{s}},-\mathrm{Si}-\mathrm{O}\right.$ linked with quartz microcrystal), $1050 \mathrm{~cm}^{-1}$ ( $v_{\text {as }}$, $-\mathrm{Si}-\mathrm{O}$ linked with quartz microcrystal), $1488 \mathrm{~cm}^{-1}, 1509 \mathrm{~cm}^{-1}$, $1558 \mathrm{~cm}^{-1}, 1580 \mathrm{~cm}^{-1}, 1606 \mathrm{~cm}^{-1}\left(-\mathrm{C}_{6} \mathrm{H}_{5}\right.$ linked with benzyl alcohol), $1798 \mathrm{~cm}^{-1}$ (solvent THF).

At the same time, abundant glycidyl groups on the surface of mQMC - joined together with Si-H functional bonds, vinyl groups, and MPSD — constructed a highly crosslinked network. Naturally, this predominant organosilicone nature will assign good optical properties to the quartz composites. As shown in Figure 4, transmittance of the neat organosilicone reaches nearly $90 \%$ in the visible range from $450 \mathrm{~nm}$ to $700 \mathrm{~nm}$. However, the high refractive index of mQMC is adverse to transparent blank matrix. Thus, along with increasing $\mathrm{mQMC}$ content, the composite exhibits a decreasing transmittance in the range of visible light.

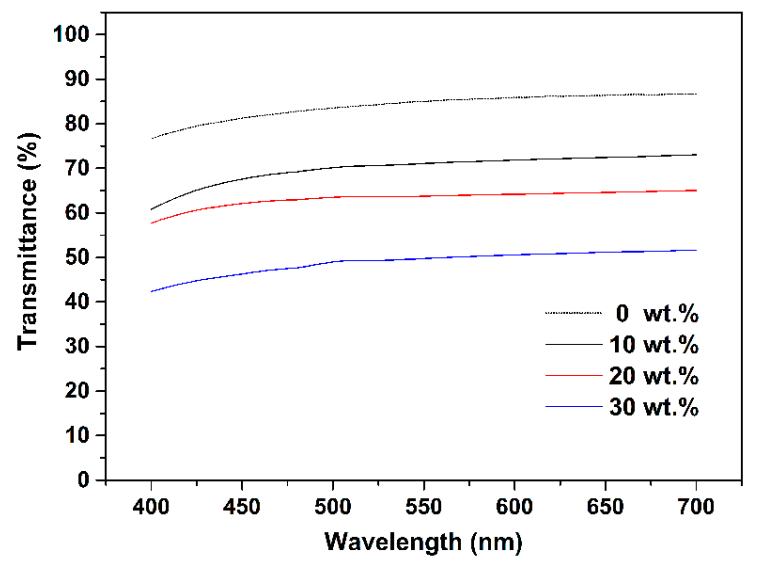

Figure 4. Transmittance curves of quartz-organosilicone composites with different mQMC contents in the visible spectrum. 
Contrary to the falling transmittance, the refractive index of quartz-organosilicone composite rises from initial 1.613 to 1.623 at the loading of $30 \mathrm{wt}$. \%. Surprisingly, the refractive index of the neat sample reaches a very high level of over 1.6, which is much larger than that of siloxane-hybridized materials with high refractive index in the previously reported works $[8,20]$. This performance may mainly attribute to the crosslinker we selected. According to the classic electromagnetic theory, the refractive index is derived from Lorentz-Lorenz equation [33]

$$
P=\frac{n^{2}-1}{n^{2}+1} \times \frac{M}{\rho}
$$

where $P$ is the molar polarization, $n$ is the refractive index of quartz-organosilicone, $M$ is the molecular weight, and $\rho$ is the density. Obviously, the refractive index has a positive correlation with the material polarization. As the key crosslinker, MPSD gives this framework plenty of benzyl groups to improve material polarization, which explains the extremely high refractive index of blank sample. On the other hand, as the content of filler increases, more and more benzyl groups of $\mathrm{mQMC}$ are introduced into the composite. Of course, high refractive index of $\mathrm{mQMCs}$ themselves is also a favorable factor. As revealed in Figure 5, the refractive index shows a good liner relation with the content of mQMC. It agrees well with the idea that the chemical structure is a critical factor in enhancing the refractive index of materials from the formula above [33].

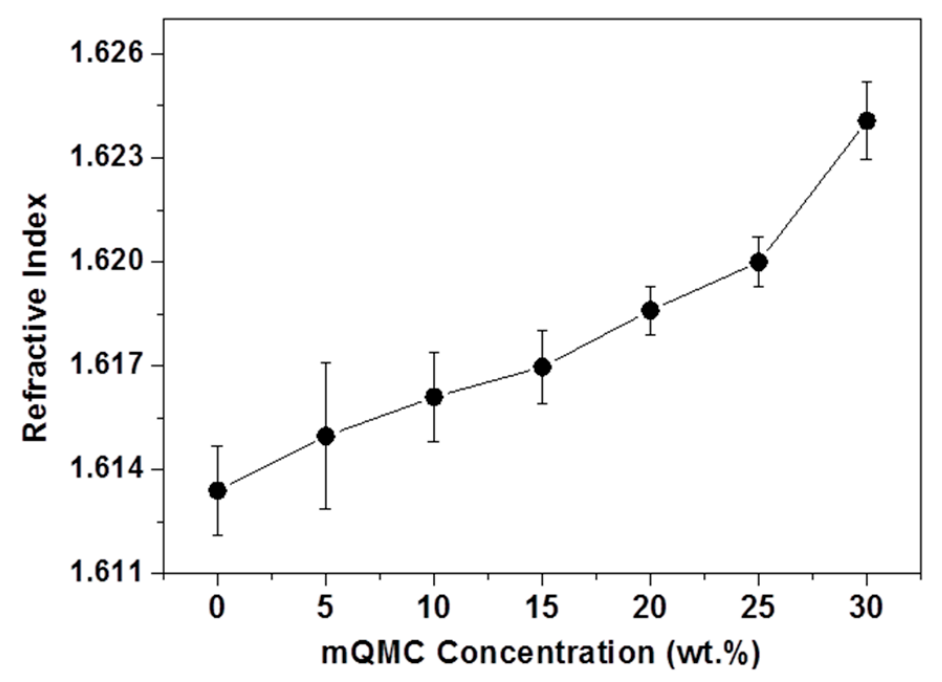

Figure 5. Refractive indexes of quartz-organosilicone composites with different mQMC contents.

Afterwards, the thermal performances of this highly crosslinked organosilicone network, including thermal stability and conductivity, are evaluated in detail. Figure 6 firstly exhibits high thermal stability of quartz-organosilicone composites. The derivatives of thermal spectra are presented in Figure S1. In Figure 6, for blank sample, 5\% weight loss temperature is $356{ }^{\circ} \mathrm{C}$, much higher than the common encapsulants [6]. As the content of mQMC filler rises above $20 \mathrm{wt}$ \%, a 5\% weight loss temperature develops from $356{ }^{\circ} \mathrm{C}\left(0 \mathrm{wt}\right.$. \%) to $361{ }^{\circ} \mathrm{C}(25 \mathrm{wt} . \%$ and $30 \mathrm{wt}$. \%). This is different from the $\mathrm{ZrO}_{2}$ particle which is able to disturb the crosslinking network [3]. 


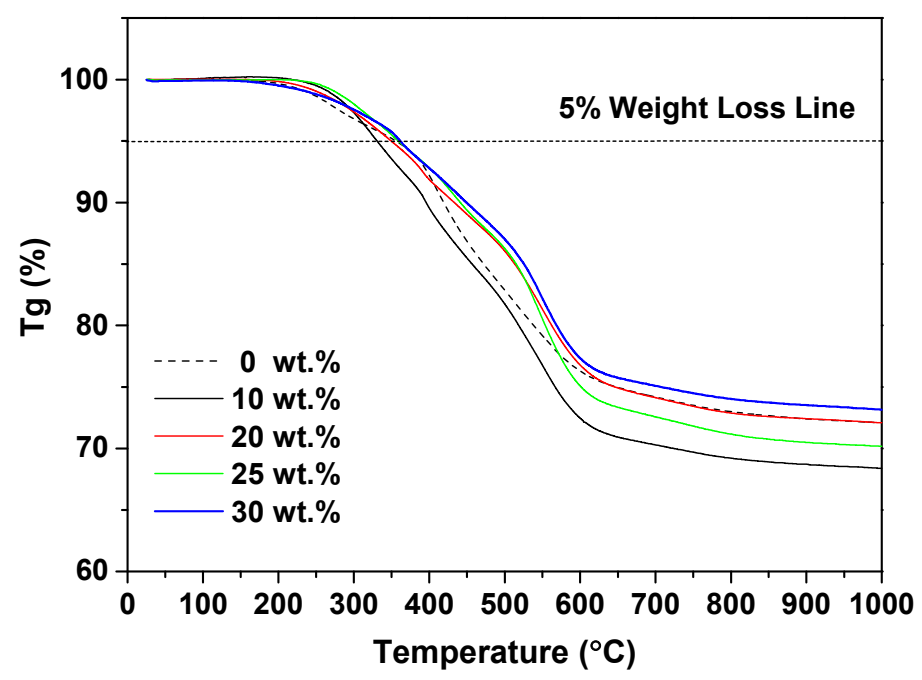

Figure 6. Thermogravimetric curves of quartz-organosilicone composites with different mQMC contents.

Except thermal stability, heat diffusion is a serious problem for encapsulant which influences the performance of electronic devices even the lifetime. For improving thermal conductivity of encapsulant, QMC (about $8 \mathrm{~W} /(\mathrm{m} \cdot \mathrm{K})$ ) is specifically chosen as the critical filler in this composite. Figure 7 illustrates that, the thermal conductivity of quartz-organosilicone composite reaches to the peak at the mQMC content of $25 \mathrm{wt}$. \%. It may be ascribed to the distribution of highly thermoconductive QMC in the organosilicone network. At the low concentration, mQMCs are well-distributed in the matrix to make the heat flux homogeneous. Here, the enhancement of thermal conductivity is obvious. However, once the mass ratio of $\mathrm{mQMC}$ filler achieves $30 \mathrm{wt}$. \%, the aggregation of particles emerges, leading to a decrease of thermal conductivity.

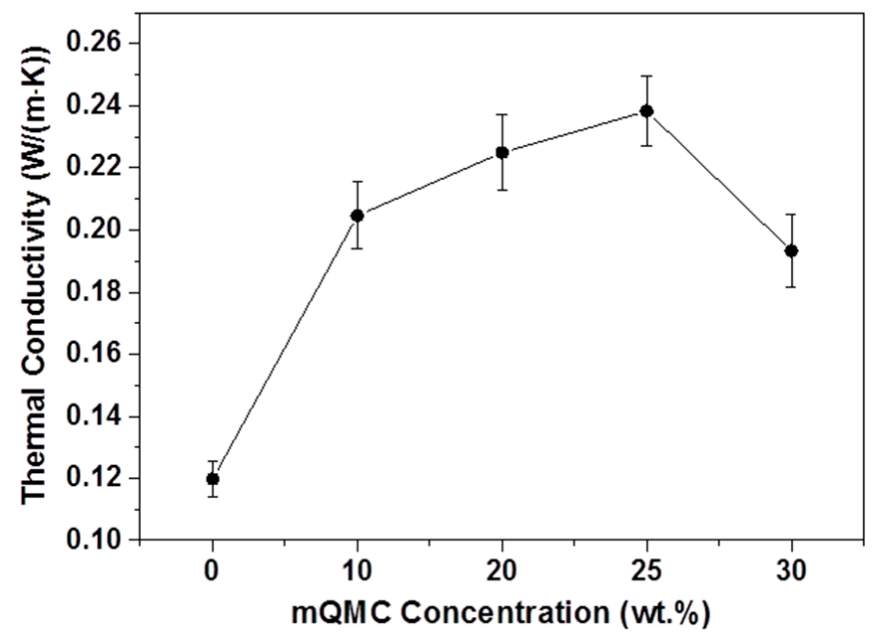

Figure 7. Thermal conductivities of quartz-organosilicone composites with different mQMC contents.

The last key parameter, the mechanical performances of quartz-organosilicone encapsulants, are represented in Figure 8. Remarkably, the highest storage modulus is obtained at the mQMC content of $30 \mathrm{wt}$ \%. As the mQMC content below $30 \mathrm{wt}$. \%, the addition of fillers does not bring any obvious variation of storage modulus. Once the content of filler reaches $30 \mathrm{wt}$. \%, the crosslinking network has formed and thus a sharp increment of storage modulus emerges, presenting an obvious reinforcing effect. Meanwhile, the TGA curves in Figure 6 also indicate that, the $30 \mathrm{wt}$. \% loading is enough to form a dense crosslinking network. Furthermore, the high storage modulus reveals that 
this kind of crosslinking quartz-organosilicone composite is strong enough to resist outer pressure during encapsulation.

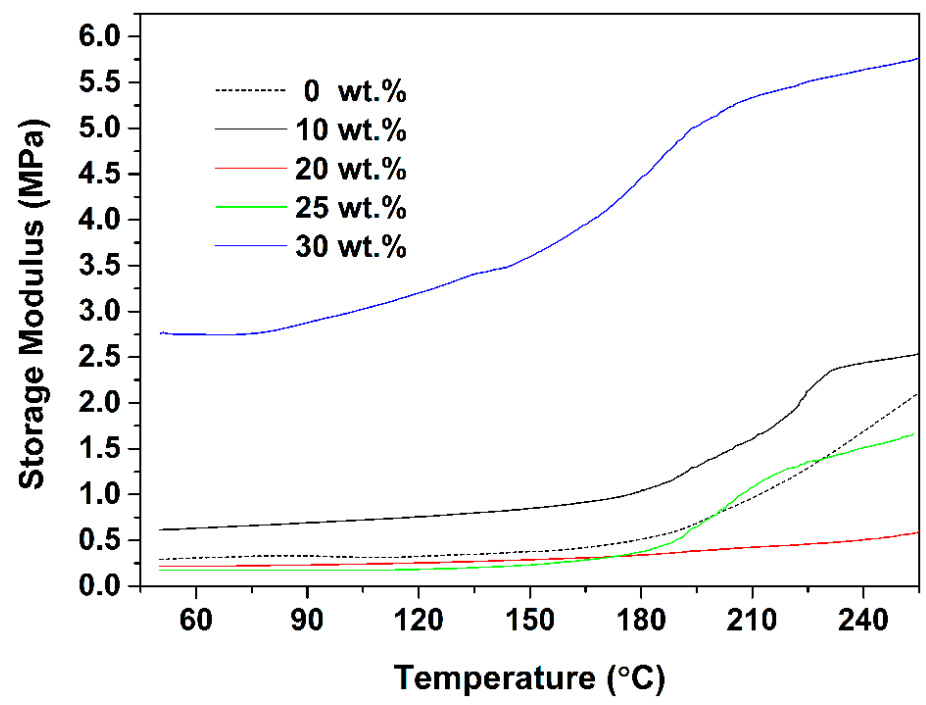

Figure 8. Dynamic mechanical thermal analyses of quartz-organosilicone composites with different mQMC contents in shear mode.

\section{Conclusions}

In this study, both compatible QMC and novel crosslinker MPSD were introduced into one in situ crosslinked organosilane matrix as high performance encapsulant. In this case, surface modified QMC as high density crosslinks can greatly increase the crosslinking degree of the organosilane composite to improve thermal stability and mechanical performance. Their high thermal conductivity also facilitates the overall thermal diffusion in the system with about double the coefficient of heat conductivity $(0.238 \mathrm{~W} /(\mathrm{m} \cdot \mathrm{K}))$. The only drawback is the falling transmittance along with increasing mQMC feeds. Moreover, MPSD possesses a more appropriate molecular rigidity compared with common diphenyl silanediol and dimethyl silanediol, so that it can integrate numerous phenyls on the surface of QMC into the organosilane encapsulant to create a very high refractive index $(\sim 1.623)$ and greatly enhance storage modulus. In view of cost, performance, and system compatibility, this highly crosslinked quartz-organosilane composite is anticipated to be a good encapsulant candidate for improving reliability of OLEDs.

Supplementary Materials: The following are available online at www.mdpi.com/2073-4360/10/1/84/s1, Figure S1: Thermogravimetric curves of quartz-organosilicone composites with different mQMC contents. (a) 0 wt.\%, (b) 10 wt.\%, (c) 20 wt.\%, (d) 25 wt.\% and (e) $30 \mathrm{wt} . \%$.

Acknowledgments: This work was financially supported by the National Key Research and Development Program of China (No. 2016YFB0401501), National Natural Science Foundation of China (51561135014, U1501244), Guangdong Innovative Research Team Program (No. 2013C102), Guangdong Province Major Science and Technology Projects (No. 2015B090913004), Special Fund on Public Interest Research and Capacity Building in Guangdong Province (No. 2016A010101023), Key Cultivation Project of Basic Research of Guangdong Natural Science Foundation (No. 2014A030308013), Guangdong Provincial Key Laboratory of Optical Information Materials and Technology (No. 2017B030301007), MOE International Laboratory for Optical Information Technologies, and the 111 Project.

Author Contributions: Hao Li conceived and designed the experiments; Xin Chen, Xiao Wang, and En Li performed the experiments; Yancong Feng analyzed the data and made the figures; Lingling Shui, Yao Wang, and Nan Li provided some suggestions for this project; Hao Li, Yancong Feng, and Xin Chen wrote the manuscript; Guofu Zhou helped revise the manuscript. All authors critically reviewed the manuscript.

Conflicts of Interest: The authors declare no conflict of interest. 


\section{References}

1. De Mello, J.; Anthony, J.; Lee, S. Organic electronics: Recent developments. Chemphyschem 2015, 16, 1099-1100. [CrossRef] [PubMed]

2. Thejo Kalyani, N.; Dhoble, S.J. Novel materials for fabrication and encapsulation of OLEDs. Renew. Sustain. Energy Rev. 2015, 44, 319-347. [CrossRef]

3. Tao, P.; Li, Y.; Siegel, R.W.; Schadler, L.S. Transparent dispensible high-refractive index $\mathrm{ZrO}_{2} /$ epoxy nanocomposites for LED encapsulation. J. Appl. Polym. Sci. 2013, 130, 3785-3793. [CrossRef]

4. Li, T.; Zhang, J.; Wang, H.; Hu, Z.; Yu, Y. High-performance light-emitting diodes encapsulated with silica-filled epoxy materials. ACS Appl. Mater. Interfaces 2013, 5, 8968-8981. [CrossRef] [PubMed]

5. Yang, S.; Kwak, S.-Y.; Jin, J.; Kim, J.-S.; Choi, Y.; Paik, K.-W.; Bae, B.-S. Thermally resistant UV-curable epoxy-siloxane hybrid materials for light emitting diode (LED) encapsulation. J. Mater. Chem. 2012, 22, 8874-8880. [CrossRef]

6. Chen, Z.; Liu, Z.; Shen, G.; Wen, R.; Lv, J.; Huo, J.; Yu, Y. Effect of chain flexibility of epoxy encapsulants on the performance and reliability of light-emitting diodes. Ind. Eng. Chem. Res. 2016, 55, 7635-7645. [CrossRef]

7. Chen, J.; Huang, X.; Zhu, Y.; Jiang, P. Cellulose nanofiber supported 3D interconnected BN nanosheets for epoxy nanocomposites with ultrahigh thermal management capability. Adv. Funct. Mater. 2017, 27, 1604754. [CrossRef]

8. Kim, J.-S.; Yang, S.; Bae, B.-S. Thermally stable transparent sol-gel based siloxane hybrid material with high refractive index for light emitting diode (LED) encapsulation. Chem. Mater. 2010, 22, 3549-3555. [CrossRef]

9. Lee, S.; Hong, J.Y.; Jang, J. Multifunctional graphene sheets embedded in silicone encapsulant for superior performance of light-emitting diodes. ACS Nano 2013, 7, 5784-5790. [CrossRef] [PubMed]

10. Varenik, M.; Nadiv, R.; Levy, I.; Vasilyev, G.; Regev, O. Breaking through the solid/liquid processability barrier: Thermal conductivity and rheology in hybrid graphene-graphite polymer composites. ACS Appl. Mater. Interfaces 2017, 9, 7556-7564. [CrossRef] [PubMed]

11. Bartlett, M.D.; Kazem, N.; Powell-Palm, M.J.; Huang, X.; Sun, W.; Malen, J.A.; Majidi, C. High thermal conductivity in soft elastomers with elongated liquid metal inclusions. Proc. Natl. Acad. Sci. USA 2017, 114, 2143-2148. [CrossRef] [PubMed]

12. Bae, J.-Y.; Kim, H.-Y.; Lim, Y.-W.; Kim, Y.-H.; Bae, B.-S. Optically recoverable, deep ultraviolet (UV) stable and transparent sol-gel fluoro siloxane hybrid material for a UV LED encapsulant. RSC Adv. 2016, 6, 26826-26834. [CrossRef]

13. Chen, M.; Zhang, G.Y.; Liang, X.; Zhang, W.S.; Zhou, L.; He, B.F.; Song, P.; Yuan, X.; Zhang, C.H.; Zhang, L.Y.; et al. Thermally stable transparent sol-gel based active siloxane-oligomer materials with tunable high refractive index and dual reactive groups. RSC Adv. 2016, 6, 70825-70831. [CrossRef]

14. Kleine, T.S.; Nguyen, N.A.; Anderson, L.E.; Namnabat, S.; LaVilla, E.A.; Showghi, S.A.; Dirlam, P.T.; Arrington, C.B.; Manchester, M.S.; Schwiegerling, J.; et al. High refractive index copolymers with improved thermomechanical properties via the inverse vulcanization of sulfur and 1,3,5-triisopropenylbenzene. ACS Macro Lett. 2016, 5, 1152-1156. [CrossRef]

15. Sun, Z.; Huang, H.; Li, L.; Liu, L.; Chen, Y. Polythioamides of high refractive index by direct polymerization of aliphatic primary diamines in the presence of elemental sulfur. Macromolecules 2017, 50, 8505-8511. [CrossRef]

16. Kim, Y.H.; Kim, H.; Yeo, H.; Goh, M.; Ku, B.-C.; Hahn, J.R.; You, N.-H. Preparation of UV-curable acryl resin for high refractive index based on 1,5-bis(2-acryloylenethyl)-3,4-ethylenedithiothiophene. Eur. Polym. J. 2016, 75, 303-309. [CrossRef]

17. Nakabayashi, K.; Imai, T.; Fu, M.-C.; Ando, S.; Higashihara, T.; Ueda, M. Poly(phenylene thioether)s with fluorene-based cardo structure toward high transparency, high refractive index, and low birefringence. Macromolecules 2016, 49, 5849-5856. [CrossRef]

18. Hsu, C.-Y.; Han, W.-G.; Chiang, S.-J.; Su, W.-C.; Liu, Y.-L. Multi-functional branched polysiloxanes polymers for high refractive index and flame retardant LED encapsulants. RSC Adv. 2016, 6, 4377-4381. [CrossRef]

19. Liu, Y.; Lin, Z.Y.; Moon, K.-S.; Yoo, S.; Choi, J.; Wong, P. High refractive index and transparency nanocomposites as encapsulant for high brightness LED packing. Electron. Compon. Technol. Conf. 2013, 4, 553-556. 
20. Macdonald, E.K.; Lacey, J.C.; Ogura, I.; Shaver, M.P. Aromatic polyphosphonates as high refractive index polymers. Eur. Polym. J. 2017, 87, 14-23. [CrossRef]

21. Chung, P.T.; Chiou, S.H.; Tseng, C.Y.; Chiang, A.S. Preparation and evaluation of a zirconia/oligosiloxane nanocomposite for LED encapsulation. ACS Appl. Mater. Interfaces 2016, 8, 9986-9993. [CrossRef] [PubMed]

22. Kim, Y.H.; Lim, Y.-W.; Lee, D.; Kim, Y.H.; Bae, B.-S. A highly adhesive siloxane LED encapsulant optimized for high thermal stability and optical efficiency. J. Mater. Chem. C 2016, 4, 10791-10796. [CrossRef]

23. Ireni, N.G.; Karuppaiah, M.; Narayan, R.; Raju, K.V.S.N.; Basak, P. TiO 2 /poly(thiourethane-urethane)-urea nanocomposites: Anticorrosion materials with NIR-reflectivity and high refractive index. Polymer 2017, 119, 142-151. [CrossRef]

24. Wang, F.; Zeng, X.; Yao, Y.; Sun, R.; Xu, J.; Wong, C.P. Silver nanoparticle-deposited boron nitride nanosheets as fillers for polymeric composites with high thermal conductivity. Sci. Rep. 2016, 6, 19394. [CrossRef] [PubMed]

25. Wang, F.; Zeng, X.; Yao, Y.; Gong, Z.; Wang, F.; Sun, R.; Xu, J.; Wong, C.P. Ice-templated assembly strategy to construct 3D boron nitride nanosheet networks in polymer composites for thermal conductivity improvement. Small 2015, 11, 6205-6213.

26. Zhu, J.; Park, H.; Chen, J.-Y.; Gu, X.; Zhang, H.; Karthikeyan, S.; Wendel, N.; Campbell, S.A.; Dawber, M.; $\mathrm{Du}, \mathrm{X}$; ; et al. Revealing the origins of 3D anisotropic thermal conductivities of black phosphorus. Adv. Electron. Mater. 2016, 2, 1600040. [CrossRef]

27. Wang, Z.; Lu, Z.; Mahoney, C.; Yan, J.; Ferebee, R.; Luo, D.; Matyjaszewski, K.; Bockstaller, M.R. Transparent and high refractive index thermoplastic polymer glasses using evaporative ligand exchange of hybrid particle fillers. ACS Appl. Mater. Interfaces 2017, 9, 7515-7522. [CrossRef] [PubMed]

28. Yao, Y.; Zeng, X.; Pan, G.; Sun, J.; Hu, J.; Huang, Y.; Sun, R.; Xu, J.B.; Wong, C.P. Interfacial engineering of silicon carbide nanowire/cellulose microcrystal paper toward high thermal conductivity. ACS Appl. Mater. Interfaces 2016, 8, 31248-31255. [CrossRef] [PubMed]

29. Zhou, Y.; Wang, L.; Zhang, H.; Bai, Y.; Niu, Y.; Wang, H. Enhanced high thermal conductivity and low permittivity of polyimide based composites by core-shell $\mathrm{Ag@SiO}$ nanoparticle fillers. Appl. Phys. Lett. 2012, 101, 012903. [CrossRef]

30. Peters, J.E.; Papavassiliou, D.V.; Grady, B.P. Unique thermal conductivity behavior of single-walled carbon nanotube-polystyrene composites. Macromolecules 2008, 41, 7274-7277. [CrossRef]

31. James, A.C.; John, C.C. Procedures for preparation of silanols. J. Organomet. Chem. 1994, 480, $23-26$.

32. Kim, Y.H.; Bae, J.Y.; Jin, J.; Bae, B.S. Sol-gel derived transparent zirconium-phenyl siloxane hybrid for robust high refractive index LED encapsulant. ACS Appl. Mater. Interfaces 2014, 6, 3115-3121. [CrossRef] [PubMed]

33. Chen, S. Molecular composites comprising $\mathrm{TiO}_{2}$ and their optical properties. Macromolecules 2008, 41, 4838-4844.

(C) 2018 by the authors. Licensee MDPI, Basel, Switzerland. This article is an open access article distributed under the terms and conditions of the Creative Commons Attribution (CC BY) license (http://creativecommons.org/licenses/by/4.0/). 